\title{
Editorial
}

\section{Supporting Academic Freedom and Living Societal Responsibility}

\author{
The Role of Authors, Reviewers, and Editors \\ in the Publication Process at EJPA
}

\author{
Dragos Iliescu ${ }^{1}$, Samuel Greiff ${ }^{2}$, René Proyer ${ }^{3}$, Matthias Ziegler ${ }^{4}$, Mark Allen ${ }^{5}$, \\ Laurence Claes ${ }^{6}$, Marjolein Fokkema7, Penelope Hasking ${ }^{8}$, Annemarie Hiemstra ${ }^{9}$, \\ Marlies Maes ${ }^{10}$, Marcus Mund ${ }^{11}$, Chris Nye ${ }^{12}$, Ronny Scherer ${ }^{13}$, Eunike Wetzel ${ }^{14}$, \\ and Pia Zeinoun ${ }^{15}$ \\ 1 Faculty of Psychology and Educational Sciences, University of Bucharest, Romania \\ ${ }^{2}$ Institute of Cognitive Science and Assessment (COSA), University of Luxembourg, Luxembourg \\ ${ }^{3}$ Institut für Psychologie, Differentielle Psychologie und Persönlichkeitsforschung, University of Halle-Wittenberg, Germany \\ ${ }^{4}$ Department of Psychology, Humboldt University Berlin, Germany \\ 5 School of Psychology, University of Wollongong, NSW, Australia \\ ${ }^{6}$ Department of Psychology, Catholic University Leuven, Belgium \\ 7 Deparment of Methods \& Statistics, University Leiden, The Netherlands \\ 8 School of Psychology \& Speech Psychology, Curtin University, Bentley, WA, Australia \\ ${ }^{9}$ Erasmus School of Social and Behavioural Sciences, Erasmus University Rotterdam, The Netherlands \\ 10 Department of Interdisciplinary Social Science, Utrecht University, The Netherlands \\ 11 Department of Psychology, Friedrich-Schiller-Universität Jena, Germany \\ 12 Department of Psychology, Michigan State University, East Lansing, MI, USA \\ ${ }^{13}$ Centre for Educational Management, University of Oslo, Norway \\ 14 Department of Psychology, Otto-von-Guericke-Universität Magdeburg, Germany \\ 15 Beit Misk, El Maten, Lebanon
}

Scientific debates and controversy abound in all fields of research and are integral parts of the scientific discourse. In fact, they are rightfully considered the driving forces behind scientific advancement and are inherent to the scientific process. Research on psychological assessment is no exception to this: Questions such as the right approach to measuring psychological constructs, dimensionality and factor structures of data from such measures, inclusion and exclusion of items, validity evidence for scores from measurement instruments, and many other issues have been approached (mostly empirically) by researchers interested in psychological assessment.

At times topics of interest for academics coincide or are directly intertwined with societal discussions and controversies. A recent example is a COVID-19 pandemic that showcases in many ways how the (quickly evolving) body of scientific knowledge feeds into different (political) narratives (Verma, 2020) or sometimes into extreme conspirational beliefs. Another example is systemic racism, which has recently been at the center of a number of discussions also within the scientific community and that has led to editorial actions in other journals (Bauer, 2020). Within the history of psychology there are many debates touching upon this specific issue (e.g., Wicherts, Borsboom, et al., 2010; Wicherts, Dolan, et al., 2010). A closer look at the arguments within such debates reveals that the quality of the measures used often is a focal discussion point. ${ }^{1}$ Thus, research on psychological assessment and the quality

\footnotetext{
${ }^{1}$ It is not the topic of the current editorial but taking this argument into account we want to highlight the importance of courses on psychological
} assessment in the curricula of psychology and caution against ideas of reducing assessment-related courses in psychology programs. 
of the tools used in psychological research is a vital aspect within a recently rekindling debate regarding academic freedom and societal responsibility making this topic relevant for European Journal of Psychological Assessment (EJPA).

Whenever scientific discussions such as the one mentioned above flare-up, another discussion usually ensues: Should science, driven by academic freedom, investigate questions that potentially provide extremists from all stripes with arguments for their ideology? Or should societal responsibility prevent science from touching upon such issues that have the potential to be misused for extremists' purposes?

As editors of EJPA, we are interested in finding ways through which to solve such potential deep value disagreements in a reasonable way - we consider this a philosophical issue of paramount importance when one strives at balancing political or religious values and principles on one hand, with the freedom of seeking the truth through science on the other hand.

From this, it is easy to conclude that authors, reviewers, readers, and editors - in fact, every scientist - need to be aware of and find a way of responsibly dealing with societal discussions and controversies related to research or its findings while at the same time cherishing academic freedom. This is, by no means, a new insight but one that has recently gained traction and that now seems more important than ever.

One argument that is often used to counter the societal responsibility of researchers, in particular when it comes to controversial findings, is, as already mentioned, academic freedom. Here, we follow Lovejoy's (1930 cited from Dobson, 1997, p. 244) definition of academic freedom as the "freedom to investigate and discuss the problems of his/her; the scientist's science and to express his/her conclusions .... without interference from political or ecclesiastical authorities, or from the administrative officials of the institution in which he/she is employed". In Lovejoy's definition, academic freedom is in opposition to political and ecclesiastical tyranny, as forms of hard, formal, but still socially legitimized power; in modern democratic societies, these forms of hard pressure and potential censorship have ceased to exist and have been replaced by what is currently defined as societal responsibility. In any case, according to this definition, academic freedom is a far-reaching privilege and, indeed, academic freedom is a guiding principle for many modern universities and research facilities that is often protected by law. The idea that research is judged on its scientific merits alone is a principle that entire research communities rely on and it is a paramount principle - theoretically speaking.

Why theoretically speaking? Because if it is considered in isolation, it assumes implicitly that science and scientists are contained in isolation, that is in the scientific ivory tower with little to no connection to "the outside world" and to society and politics in a way that might reach beyond the mere content-related dispute of the scientific finding. Along these lines, Barnhizer (1993) describes the concept of the ivory tower as a passive mode. But neither science nor scientists are passive and in a global world, it is unrealistic to assume that scientists do not actively participate in society and also in political discourse. The current COVID-19 pandemic is a prime example of the relevance of scientific findings for political decision-making (Bavel et al., 2020). In practice, research is often political or, to say the least, it is used for political narratives. With this in mind, academic freedom is not a self-serving principle, but a two-way street. While one direction of this street can be described as academic freedom, the other is academic responsibility toward society. Put differently, academic freedom is inherently tied to the obligation that research serves society and works toward a better society (De George, 2003). Thus, the other side of the coin of academic freedom is that to the extent that research institutions and the individuals working therein are part of society, they also have a (moral) obligation to serve this society.

As a consequence, we have to balance two guiding principles: Academic freedom and academic responsibility toward society. Often, they might go hand in hand and the freedom of researching a vaccine for COVID-19 might simultaneously pay justice to academic responsibility toward society. Fortunately, in most cases, there is no disconnect between academic freedom and academic responsibility. What happens, though, when the two principles are in conflict with each other? To be clear up front: There is no straightforward answer to this question, which is - in essence - a theoretical and philosophical one. It is a valuedriven and moral decision (and not a correct/incorrect response as we sometimes see in psychological assessment) how to weigh them against each other in cases they conflict.

When finding oneself in a situation where academic freedom and societal responsibility seem to clash, we strongly argue for value-driven, moral decision-making that would likely place the final decision in the middle ground between academic freedom and societal responsibility. We believe that possible radical stances are (as lies in the nature of radical stances) weak and often ridiculous when evaluated in more detail. Radically embracing academic freedom while completely ignoring societal responsibility could lead to researchers being completely disengaged from the use of their research and handing anyone a carte blanche for misusage and misinterpretation. We know how often scientific conclusions are only tentative, how often they need to be corroborated with other scholarly resources, and how often they are subject to change and refinement upon 
further research - as we also know how sometimes this is either misunderstood by naive readers or simply willingly ignored by interested parties. Radically embracing responsibility toward society while completely ignoring academic freedom could lead to both active censorship and passive self-censorship, and could easily generate, especially in the current, ideologically charged Zeitgeist, a clone of Orwell's 1984. This is exactly the situation against which academic freedom was meant to guard in the first place: Currently dominating ideologies deciding what can be researched and what can be disseminated.

In this Editorial, we outline our current vision on how academic freedom and academic responsibility need to both be considered and weighed against each other in a sensible and careful way by editors, authors, reviewers, and readers of EJPA. We will also outline how we adapt the submission and publication process in our journal toward ensuring a balance between academic freedom and academic responsibility - based on the notion that psychological assessment plays an important role in psychological research and beyond, and has the potential to inform decision-making, not only for individuals but also in larger contexts (e.g., in educational settings or policymaking in general).

The issue of how to balance or even reconcile academic freedom and academic responsibility with regard to potentially controversial findings is not new but it is currently discussed (e.g., Bauer, 2020). Of note, history is full of examples where societal responsibility has been used as an excuse to waive academic responsibility and, just the other way around, societal responsibility has been used to restrict academic freedom. Both psychologies as a discipline as well as the psychological assessment are no exceptions to this, and history teaches us that we should be mindful of both principles. This notion is even more important in a time where societal inequalities come to light very clear once more, and where there is heightened awareness that new solutions are needed to societal challenges and inequalities across the globe.

Our (admittedly subjective) view is that when it comes to societal responsibility in the context of politically controversial research, this responsibility should be a shared one: It is the authors' responsibility because it is their paper and they are responsible for the content; it is the editors' responsibility because they ultimately made the decision to have a paper peer-reviewed or, later, to publish that paper; it is the reviewers' responsibility because they allowed this to pass their critical evaluation; it is the readers' responsibility because they interpret science in a way that feeds their narrative and they use or misuse it. All these assertions are wrong in their absoluteness, but they are right in the way that in a model of shared responsibility all of these parties have responsibility. Combining this diffusion of responsibility with the well-known fallacies of peer review (e.g., Trafimow \& Rice, 2009) and the complexity of many of the processes involved in science and its publication, one can easily see that - even without any bad intention - sometimes academic responsibility gets lost along the way. Of course, matters are worse when there is an intention to misuse scientific results for political motives.

Nobody can avoid that some of the research that is published will be politically controversial and might (however unexpectedly) feed into some kind of political narrative, and neither can we. And academic freedom is a high standard that has been established for good reasons. It allows researchers to publish even controversial findings as long as they are judged on their scientific merits. Interestingly, there are positions that claim that scientific disputes can only be solved within the discipline as only the discipline provides the relevant expertise (De George, 2003). Here, we would like to extend this view by saying that in case there is a scientific dispute ongoing within the discipline, everybody involved in the publication process needs to be mindful and take preventive actions to allow for a balanced positioning that cannot be misused for political agendas. In this, we at EJPA are aware that we will not be able to prevent controversy (and we hereby mean political controversy - as we very much wish for scientific controversy to be present), but we want to take reasonable steps to maximize the chances for balanced and mindful representations of discrepant ideas and positions.

In order to be published, a paper first needs to pass through the editor's scrutiny. Usually, we judge a paper regarding its fit with the journal's scope and based on whether it would have a chance in the peer-review process given its general scientific quality. The latter also means that the study presented should stand on firm theoretical grounds, be based on high-quality data, and use adequate statistical analyses and interpretations. However, it cannot be ruled out that papers are submitted that rely on controversial and potentially politically motivated theorizing. At first sight, this might seem of peripheral importance to an assessment journal. However, the ABC of test construction, which the EJPA adheres to (Ziegler, 2014), clearly calls for a robust theoretical anchoring and specific a-priori hypotheses for much of the evidence provided to support a test score interpretation, this part of the paper is of utmost importance. Here, it is the editor's responsibility to judge the soundness of the theoretical foundation provided and anticipate potential influence on existing societal controversies like the one surrounding systemic racism. As a consequence, we propose the following new guideline for EJPA: 
The journal will not publish articles that rely on scientifically unsound or no scientific theories, ${ }^{2}$ do not contain convincing data or do not use adequate methods. ${ }^{3}$ As in the past, the editors will judge whether that is the case.

Once a paper has reached the stage of peer-review, it becomes the reviewers' responsibility to balance academic freedom and societal responsibility. Here, we will try to raise reviewers' awareness by including a standard reviewer question on the potential for use in political controversies.

So, what if a submitted paper is judged on its scientific merits and deemed suitable for eventual publication, but contains findings that are likely politicized and might feed into extremist agendas? The extreme positions are to (1) use academic freedom as a rule that trumps any other and to publish it as is or to (2) rejects it on the basis that it does not serve the good of society. At EJPA, at this point we choose a middle ground between these positions. Up until now, we have tried to take care of these aspects implicitly, but we believe that one important step toward more transparency will be to address these aspects more explicitly.

To this end, the submission/publication process at EJPA will be amended in the ways outlined below.

(1) The journal will not publish articles that rely on scientifically unsound or no scientific theories, do not contain convincing data, or do not use adequate methods. The editors will judge whether that is the case (see also above). This holds for papers that may fuel ideological controversies, but, of course, also for all other papers.

(2) Authors will be required to state clearly how far the cumulated evidence supports the use of the presented findings for the uses intended; in case this is not already stated clearly in the manuscript, the editors will require explicit statements in this regard.

(3) Reviewers will routinely be asked to evaluate the potential that a paper could be used in political debates.

If the potential for political implications or association with societal controversies is detected, the authors may be asked at any time during the review process for one or more of the following:

(a) Authors will be required to provide an explanation on how they dealt with the issue of potential political controversy and how they ensured a balanced account that bears the minimal potential for misuse (in the sense of balancing academic freedom and academic responsibility).

(b) Authors will be required to provide a clearly labeled "limitations" section as part of their manuscript that discusses limitations in the samples, in the measures, in generalizability, and so forth, when looking at it from a political and societal perspective.

(c) Authors will be informed that there might be an editorial statement or a joint statement drafted by editors and authors published alongside the paper to give readers guidance on the potential political impact and where caution is warranted in the interpretation of its limits.

(d) Beyond these measures, the editors might decide for some papers to publish reflections, comments, or brief reviews by experts in the field that put the research topic in a broader (societal) context, discuss its strengths and weaknesses, and initiate a discussion alongside the publication in question.

We are aware that we are not the first to introduce such measures and we also acknowledge that we have little experience in predicting their effect. To this end, we remain open to adapt and amend the measures mentioned above as we gather experience with it and as the discussion on academic freedom and academic responsibility evolves. We are also happy to engage in a discussion with everybody interested in the field of psychological assessment and EJPA - please feel free to contact us at ejpaeditor@gmail.com. We feel that, as a first step, the above-mentioned measures will contribute to responsible conduct in the field of psychological assessment and we hope that, through this, we can further awareness of both academic freedom and academic responsibility. In writing this editorial and in taking these measures, we want to go beyond a mere acknowledgment of philosophical principles but take direct actions. We at EJPA are excited to see what their effects will be.

\section{References}

Barnhizer, D. R. (1993). Freedom to do what? Institutional neutrality, academic freedom and academic responsibility. Journal of Legal Education, 43, 346-357.

Bauer, P. J. (2020). A call for greater sensitivity in the wake of publication controversy. Psychological Science, 31, 767-769. https://doi.org/10.1177/0956797620941482

\footnotetext{
${ }^{2}$ In other areas of science, this is not necessarily the case, as exploratory research may not be theory-driven but may still be worth publishing. Research on psychological assessment differs from these other areas of science: the development of valid measurement necessitates the existence and operationalization of theories.

${ }^{3}$ For clarity, EJPA will continue to publish exploratory studies on assessment-related research questions that fit the EJPA scope, contain convincing data, and use adequate methods. The editors will judge whether the exploratory approach is warranted in light of existing psychometric and subject-related theories.
} 
Bavel, J., Baicker, K., Boggio, P. S., Capraro, V., Cichocka, A., Cikara, M., Crockett, M. J., Crum, A. J., Douglas, K. M., Druckman, J. N., Drury, J., Dube, O., Ellemers, N., Finkel, E. J., Fowler, J. H., Gelfand, M., Han, S., Haslam, S. A., Jetten, J., ... Willer, R. (2020). Using social and behavioural science to support COVID19 pandemic response. Nature Human Behaviour, 4(5), 460471. https://doi.org/10.1038/s41562-020-0884-z

De George, R. T. (2003). Ethics, academic freedom and academic tenure. Journal of Academic Ethics, 1, 11-25. https://doi.org/ 10.1023/A:1025421706331

Dobson, K. S. (1997). The other side of academic freedom is academic responsibility. Canadian Psychology, 38, 244-247. https://doi.org/10.1037/0708-5591.38.4.244

Trafimow, D., \& Rice, S. (2009). What if social scientists had reviewed great works of the past?. Perspectives on Psychological Science, 4, 65-78. https://doi.org/10.1111/j.17456924.2009.01107.x

Verma, R. (2020). China's diplomacy and changing the COVID-19 narrative. International Journal: Canada's Journal of Global Policy Analysis, 75, 248-258. https://doi.org/10.1177/ 0020702020930054

Wicherts, J. M., Dolan, C. V., \& van der Maas, H. L. J. (2010). The dangers of unsystematic selection methods and the representativeness of 46 samples of African test-takers. Intelligence, 38, 30-37. https://doi.org/10.1016/j.intell.2009.11.003

Wicherts, J. M., Borsboom, D., \& Dolan, C. V (2010). Evolution, brain size, and the national $I Q$ of peoples around 3000 years
BC. Personality and Individual Differences, 48, 104-106. https://doi.org/10.1016/j.paid.2009.08.020.

Ziegler, M. (2014). Stop and state your intentions! Let's not forget the ABC of test construction. European Journal of Psychological Assessment, 30(4), 239-242. https://doi.org/10.1027/10155759/a000228

Published online April 15, 2021

\section{Acknowledgments}

We would like to thank Jan Dörendahl for his support in researching the background of this editorial.

\section{Editorial Note}

This editorial was drafted by the first 4 authors. All the associate editors that are listed in the author line have endorsed its content.

\section{Dragos Iliescu}

Faculty of Psychology and Educational Sciences

University of Bucharest

Sos. Panduri 90

050657 Bucharest

Romania

dragos.iliescu@fpse.unibuc.ro 